\title{
Olive oil containing olive oil fatty acid esters of plant sterols and dietary diacylglycerol reduces low-density lipoprotein cholesterol and decreases the tendency for peroxidation in hypercholesterolaemic subjects
}

\author{
Yen-Ming Chan ${ }^{1}$, Isabelle Demonty ${ }^{1}$, Dori Pelled ${ }^{2}$ and Peter J. H. Jones ${ }^{1 *}$ \\ ${ }^{1}$ The School of Dietetics and Human Nutrition, McGill University, Macdonald Campus, 21,111 Lakeshore Road, \\ Sainte-Anne-de-Bellevue, Quebec, Canada H9X $3 V 9$ \\ ${ }^{2}$ Enzymotec Ltd, Migdal HaEmeq, Israel
}

(Received 9 October 2006 - Revised 28 February 2007 - Accepted 6 March 2007)

\begin{abstract}
Plant sterols (PS) and MUFA are well-documented cholesterol lowering agents. We aimed to determine the effect of PS esterified to olive oil fatty acids (PS-OO) on blood lipid profile and lipid peroxidation in hypercholesterolaemic subjects. Twenty-one moderately overweight, hypercholesterolaemic subjects consumed three consecutive treatment diets, each lasting $28 \mathrm{~d}$ and separated by 4-week washout periods, using a randomized crossover design. Diets contained $30 \%$ energy as fat, $70 \%$ of which was provided by olive oil (OO), and differed only in the treatment oils: OO, PS esterified to sunflower oil fatty acids (PS-SO), and PS-OO. Both PS-SO and PS-OO treatments provided $1.7 \mathrm{~g}$ PS /d. PS-OO and PS-SO consumption resulted in a decrease $(P=0.0483)$ in LDL-cholesterol (LDL-C) concentrations compared with the OO diet. Although total cholesterol and apo B-100 levels were not significantly affected, PS-SO and, to some extent, PS-OO reduced the total:HDL-cholesterol (HDL-C) ratio $(P=0.0142)$ and the apo B-100:apo A-I ratio $(P=0.0168)$ compared with the OO diet. There were no differences across diets in lipoprotein(a) $(\mathrm{Lp}(\mathrm{a}))$ and lipid peroxidation levels. However, following consumption of OO and PS-SO, Lp(a) concentrations increased $(P=0 \cdot 0050$ and 0.0421, respectively), while PS-OO treatment did not affect Lp(a) levels. Furthermore, there was a decrease $(P=0 \cdot 0097)$ in lipid peroxidation levels with PS-OO treatment during the supplementation phase. Our results suggest that supplementing an OO-rich diet with PS-OO favourably alters the plasma lipid profile and may decrease the susceptibility of LDL-C to lipid peroxidation in hypercholesterolaemic subjects.
\end{abstract}

Plant sterols: Olive oil fatty acids: Blood lipids: Oxidative stress: Hypercholesterolaemic subjects: Lipid peroxidation: Lipoprotein (a): LDL cholesterol: Apo B: Diacylglycerol

CHD is the leading cause of morbidity and mortality in Western countries. An elevated concentration of LDL-cholesterol (LDL-C) is a well-established independent risk factor for atherosclerosis ${ }^{1}$. In addition, LDL oxidation has been implicated by several studies as one of the initial steps of atherogenesis, and therefore associated with higher risk of $\mathrm{CHD}^{2,3}$. Elevated concentrations of oxidised LDL have recently been identified as a strong predictor for subsequent acute CHD events in healthy men ${ }^{4}$.

Plant sterols (PS) have long been reported to have significant cholesterol-lowering properties ${ }^{5}$. Studies conducted throughout the past decades suggested that an intake of 1.5$2 \mathrm{gPS} / \mathrm{d}$ is needed to achieve an optimal LDL-C lowering effect $^{6}$. It is generally accepted that PS decrease circulating cholesterol concentrations by suppressing intestinal absorption of cholesterol due to the higher affinity of PS to micelles compared to cholesterol, resulting in less cholesterol being incorporated in chylomicrons ${ }^{7,8}$. Several reports have demonstrated that the solubility of PS may play an important role in the process of PS incorporation into micelles 9 . Indeed, low intestinal bioavailability of purified phytosterols was shown to be elevated by esterification to fatty acids, dissolving in dietary diacylglycerol (DAG) oil, or by emulsifying with lecithin micelles ${ }^{10-13}$. To date, the most common process used to enhance the solubility of PS is by esterifying PS with n-6 PUFA, such as soyabean oil and sunflower oil (SO) fatty acids. PS can therefore be incorporated into fatty foods, such as margarines and spreads ${ }^{14}$. Emerging new approaches consist of esterifying PS to fatty acids associated with additional health benefits, such as fish oil fatty acids ${ }^{15}$.

Early epidemiological evidence showed a lower incidence of CHD in Mediterranean countries ${ }^{16}$ where olive oil (OO) is the primary source of $\mathrm{fat}^{17}$. The consumption of $\mathrm{OO}$, which contains high levels of oleic acid (a MUFA), was inversely associated with IHD, presumably due to hypolipidaemic effects ${ }^{18}$. This notion has been further confirmed in several clinical intervention trials ${ }^{19-21}$. MUFA supplementation was also shown to have protective effects against lipid peroxidation ${ }^{19,22}$. Likewise, PS were also reported to have antioxidant properties ${ }^{23}$.

Abbreviations: DAG, diacylglycerol; HDL-C, HDL-cholesterol; LDL-C, LDL-cholesterol; Lp(a), lipoprotein (a); OO, Olive oil; SO, sunflower oil; PS, plant sterols; TBARS, thiobarbituric acid-reactive substance; TC, total cholesterol.

* Corresponding author: Professor Peter J. H. Jones, fax 1 (514) 398-7739; email peter.jones@mcgill.ca 
The objective of this study was to assess whether a novel formulation of PS that had been esterified with OO fatty acids (PS$\mathrm{OO})$ would exert the effects of its components on the blood lipid profile and lipid peroxidation. We tested this hypothesis in mildly overweight, hypercholesterolaemic subjects who consumed an OO-rich diet that was further supplemented either with PS-OO or with PS esterified to SO fatty acids (PS-SO).

\section{Methods}

\section{Study population}

Twenty-four volunteers (eleven males, thirteen postmenopausal females) were recruited from the Montreal area by an advertisement posted in local newspapers. The inclusion criteria were as follows: baseline LDL-C $>2.6 \mathrm{mmol} / 1$ $(100 \mathrm{mg} / \mathrm{dl})$, BMI ranging from 24 to $30 \mathrm{~kg} / \mathrm{m}^{2}$ and aged 30-65 years. Subjects were excluded if they had taken medications known to affect lipid metabolism, such as cholestyramine, colestipol, gemfibrozil, probucol, 3-hydroxy-3methylglutaryl coenzyme A (HMG-CoA) reductase inhibitors, fish oil capsules and supplements containing PS, during the previous 3 months. Subjects who had been diagnosed with diabetes mellitus, kidney disease or liver disease, and those who smoked, consumed more than two glasses per day of alcoholic beverages and/or took two or more doses per week of laxatives or concentrated sources of fibre were also excluded. Subjects with thyroid disease (n 2) and with high blood pressure $(n 4)$ were included in the study since they had been stable in response to thyroid and blood pressure treatments, and their medications were maintained throughout the trial. One subject on hormone replacement therapy was also included in the study and her regimen was maintained at the same dose throughout the study period.

Fasting blood samples were obtained for screening purposes. Before enrolment in the study, the candidates provided a medical history and underwent a complete physical examination conducted by the study physician. The study protocol was reviewed and approved by the Human Ethical Review Committee of the Faculty of Agriculture and Environmental Sciences for the School of Dietetics and Human Nutrition at McGill University (protocol number REB\# 808-0403). All subjects received explanations about the protocol and written consent forms were obtained from each participant.

\section{Experimental design, protocol and diets}

The study was a semi-randomized, crossover, double blind, clinical intervention trial using a Latin square sequence. It consisted of three $28 \mathrm{~d}$ phases separated by a 4-week washout interval. During each dietary treatment phase, the subjects were provided with an OO-based, weight-maintaining, North-American diet. During the washout period, the subjects consumed their own habitual diets. All subjects received the control OO diet during the first phase, after which they were randomly assigned to the two other dietary treatments.

The basic diet contained approximately $15 \%$ energy as protein, $55 \%$ energy as carbohydrates, $30 \%$ energy as fat, of which approximately $70 \%$ was provided by OO, $80 \mathrm{mg}$ cholesterol per $4186.8 \mathrm{~kJ} \quad(1000 \mathrm{kcal})$; and $12 \mathrm{~g}$ fibre per $4186.8 \mathrm{~kJ}(1000 \mathrm{kcal})$. The $\mathrm{OO}$ of the basic diet provided $0.02 \mathrm{~g} / \mathrm{d}$ naturally occurring free PS. The basic diet composition is shown in Table 1. Table 2 lists the composition of the treatment oils. During the two randomized phases, an isoenergetic amount of $\mathrm{OO}$ was replaced by either (i) $21.4 \mathrm{~g}$ low-fat PS-SO margarine providing the equivalent of $1.7 \mathrm{~g}$ soyabean sterols (Take control ${ }^{\circledR}$, Unilever Bestfoods NA, Baltimore, MD) or (ii) $9.1 \mathrm{~g}$ PS-OO containing the equivalent of $1.7 \mathrm{~g}$ soyabean sterols enzymatically esterified to $\mathrm{OO}$ fatty acids, as well as $1.4 \mathrm{~g}$ DAG (Enzymotec Ltd, Migdal HaEmeq, Israel). No antioxidants were supplemented to the PS-OO matrix or other tested matrices.

The diets were provided to the subjects by the Mary Emily Clinical Nutrition Research Unit at McGill University. These diets consisted of three isoenergetic meals, prepared according to a 3-d cycle menu. All meals (breakfast, lunch and supper) were prepared in the metabolic kitchen of the clinic where the foods were weighed precisely to $0.5 \mathrm{~g}$ during meal preparation. Treatment oils were ingested at breakfast and under supervision to monitor compliance. The subjects were instructed to consume only foods and beverages provided by the clinic.

All three experimental diets were isoenergetic. Individual basal energy requirements were calculated by the Mifflin equation $^{24}$, and were then multiplied by a physical activity factor of 1.7 to meet the total energy requirements of mildly to moderately active healthy adults. Energy intake was adjusted during the first 2 weeks of the control phase to maintain a constant body weight. A comparable energy level was maintained during the two subsequent phases. Subjects were encouraged to keep a constant exercise level throughout the study to ensure that body weights remained unchanged.

Fasting blood samples were collected from the subjects on days 1, 2, 28 and 29 of each phase. On day 28 of each phase, postprandial plasma TAG concentrations were measured $4 \mathrm{~h}$ after breakfast. A complete blood count was done on day 29 for monitoring purposes.

\section{Plasma lipids}

Blood samples were collected in vacutainer tubes and centrifuged for $15 \mathrm{~min}$ at $1000 \mathrm{~g}$ at $4^{\circ} \mathrm{C}$, within $30 \mathrm{~min}$, to separate plasma from erythrocytes. Plasma and erythrocytes were immediately stored at $-80^{\circ} \mathrm{C}$ until lipid analysis. Total cholesterol (TC), HDL-cholesterol (HDL-C), and TAG concentrations were measured by automated methods on the multianalyzer Dimension RxL Max utilizing enzymatic reagents Flex (Dade Behring Diagnostic, Marburg, Germany). LDL-C

Table 1. Average composition of the control olive oil-based diet over a period of $3 \mathrm{~d}$

(Values are means with their standard errors)

\begin{tabular}{lrr}
\hline Diet component & Mean & SE \\
\hline Proteins (\% energy) & 14.4 & 0.2 \\
Carbohydrates (\% energy) & 54.0 & 1.0 \\
Fat (\% energy) & 31.2 & 0.9 \\
SFA (\% energy) & 6.8 & 0.6 \\
MUFA (\% energy) & 18.6 & 0.6 \\
PUFA (\% energy) & 3.5 & 0.1 \\
Cholesterol (mg/1000 kcal) & 80.3 & 1.0 \\
Fibre (g/1000 kcal) & 12.8 & 0.3 \\
\hline
\end{tabular}


Table 2. Fatty acid and plant sterol composition of study formulations*

\begin{tabular}{|c|c|c|c|}
\hline & $\mathrm{OO}$ & PS-SO & PS-OO \\
\hline $\begin{array}{l}\text { Plant sterol esters } \\
\text { ( } \mathrm{g} / 100 \mathrm{~g} \text { oil or margarine) }\end{array}$ & ND & $12 \cdot 1$ & $28 \cdot 6$ \\
\hline \multicolumn{4}{|l|}{$\begin{array}{l}\text { Free plant sterol equivalents } \\
\text { (g/100 } \mathrm{g} \text { oil or margarine) }\end{array}$} \\
\hline$\beta$-sitosterol & 0.2 & 3.7 & $8 \cdot 4$ \\
\hline Campesterol & $>0.1$ & 1.9 & 4.6 \\
\hline Stigmasterol & $>0.1$ & 1.4 & 3.9 \\
\hline Brassicasterol & ND & 0.2 & 0.5 \\
\hline Others & 0.1 & 0.5 & 1.0 \\
\hline Total & 0.2 & $7 \cdot 8$ & $18 \cdot 3$ \\
\hline \multicolumn{4}{|l|}{$\begin{array}{l}\text { Fatty acids ( } \% \text { by weight } \\
\text { total fatty acids) }\end{array}$} \\
\hline $12: 0$ & ND & 0.2 & ND \\
\hline $14: 0$ & $>0.1$ & 0.2 & ND \\
\hline $16: 0$ & 12.9 & $8 \cdot \overline{3}$ & $12 \cdot 8$ \\
\hline $16: 1$ & 1.0 & 0.1 & 0.9 \\
\hline $17: 0$ & ND & 0.1 & ND \\
\hline $18: 0$ & 2.9 & $6 \cdot 2$ & 3.0 \\
\hline $18: 1$ & $69 \cdot 8$ & $41 \cdot 8$ & $70 \cdot 6$ \\
\hline $18: 2$ & 11.5 & $36 \cdot 4$ & $10 \cdot 7$ \\
\hline $18: 3 n-3$ & 0.8 & 5.5 & 0.8 \\
\hline $20: 0$ & 0.5 & 0.5 & 0.5 \\
\hline $20: 1$ & 0.3 & 0.3 & 0.2 \\
\hline $22: 0$ & 0.2 & 0.4 & 0.2 \\
\hline $24: 0$ & 0.1 & 0.2 & 0.1 \\
\hline Other fatty acids & 0.2 & ND & $0 \cdot 1$ \\
\hline
\end{tabular}

OO, control olive oil; PS-SO, plant sterols esterified with sunflower oil fatty acids; PS-OO, plant sterols esterified with olive oil fatty acids; ND, not detected. *Typical values.

was calculated by the Friedewald equation ${ }^{25}$ for individuals with TAG levels $<4.5 \mathrm{mmol} / \mathrm{l}$, while LDL-C was measured directly by the abovementioned enzymatic methods when TAG levels were $>4.5 \mathrm{mmol} / \mathrm{l}$. Apo A-I, apo B-100 and lipoprotein (a) ( $\mathrm{Lp}(\mathrm{a}))$ levels were measured on the BN ProSpec Nephelometer (Dade, Behring Diagnostics, Marburg, Germany) utilizing the Dade Behring $\mathrm{N}$ Antisera assays to determine apo A-I, apo B-100, and Lp(a), respectively (Behring Diagnostics).

\section{Plasma cholesterol precursor and plant sterols}

Plasma PS concentrations were determined from the non-saponifiable material of plasma lipids as reported previously ${ }^{26}$. Briefly, an internal standard, $5 \alpha$-cholestane, was added to $0.5 \mathrm{ml}$ plasma sample. Plasma samples were saponified with $0.5 \mathrm{M}$ methanolic $\mathrm{KOH}$ for $1 \mathrm{~h}$ at $100^{\circ} \mathrm{C}$ and the non-saponifiable materials were extracted with petroleum diethyl ether. After extraction, the samples were derivatized with $1.3 \mathrm{ml}$ TMS reagent (pyridine-hexamethyldisilazan-trimethylchlorosilane; 9:3:1, by volume); Sigma-Aldrich Canada Ltd, Oakville, ON, Canada). The samples were then injected into GLC (HP 5890 Series II, Hewlett Packard, Palo Alto, CA, USA), equipped with a flame ionization detection and autoinjector system and with a $30 \mathrm{~m}$ capillary column. The column temperature was $285^{\circ} \mathrm{C}$ and the isothermal running conditions were maintained for 30 minutes. Detector and injector temperatures were set to $310^{\circ} \mathrm{C}$ and $300^{\circ} \mathrm{C}$, respectively. Lathosterol, campesterol, stigmasterol and $\beta$-sitosterol peaks were identified by comparison with authenticated standards (Sigma-Aldrich Canada Ltd).

\section{Plasma lipid peroxidation}

Apo B-containing lipoproteins were precipitated with manganese chloride-heparin by ultracentrifugation ${ }^{27}$. The LDL fraction was re-suspended in normal saline after centrifugation. The thiobarbituric acidreactive substance (TBARS) assay ${ }^{28}$ was used to measure lipid peroxidation in the plasma LDL subfraction (OXItek, ZeptoMetrix Corporation, Buffalo, NY, USA).

\section{Statistical analyses}

Based on previous publications with a comparable design ${ }^{29}$, twenty subjects would be required in order to detect a clinically significant difference $(-0.48 \mathrm{mmol} / \mathrm{l})$ in LDL-C levels, the primary outcome, using $0.84 \mathrm{mmol} / \mathrm{l}$ as a standard deviation, at the 0.05 level of significance and $80 \%$ power. A total enrolment of twenty-four patients was originally estimated as being required to enable a study dropout rate of $15 \%$.

All data were expressed as means and their standard errors. Statistical significance was set at $P<0.05$ for all analyses. Variables that were not normally distributed were log transformed before analysis. Differences in plasma variables were tested by repeated-measures ANOVA with the type of dietary matrix in each intervention arm as the within-subject factor and with endpoint values as the dependent variable. Baseline values were inserted into the model as covariates if their interaction with dietary matrices was found to be statistically significant. Subsequently, contrast analyses were used to identify differences between pairs of diets. When variables failed to demonstrate any treatment effect, the two-tailed paired Student's $t$ test was used to compare baseline and endpoint values within each diet phase. Furthermore, a modified Cohen's effect size was calculated for endpoint values to evaluate changes from the baseline OO diet. Data were analyzed with the use of SAS software (version 8.0; SAS Institute Inc, Cary, NC, USA).

\section{Results}

\section{Study subjects}

Twenty-four subjects (eleven males, thirteen females) were recruited and twenty-one subjects (eleven males, ten females) completed the entire trial. The three females who dropped out during the first phase reported difficulties with the transportation to the clinic $(n 1)$ or with daily clinic visits $(n 1)$ and personal affairs $(n 1)$. The baseline characteristics of study subjects who completed the trial are displayed in Table 3. No side effects were reported after consuming the treatment oils. Results from the complete blood count at the end of each phase were within the normal range for all subjects (data not shown). The mean baseline bodyweight for $\mathrm{OO}$, PS-SO, and PS-OO (73.9 (SE 2.7) kg, 74.7 (SE 2.8) kg, and 74.4 (SE 2.8) kg, respectively) and the percentage changes in bodyweight values $(-0.7$ (SE 0.3) \%, - 0.4 (SE 0.2) \%, and -0.7 (SE 0.2 ) $\%$, respectively) did not differ between treatments. Baseline values (following washout periods) of all the characteristics presented in Table 3 were not statistically different between dietary phases (data not shown). 
Table 3. Baseline characteristics of the study subjects ( $n 11$ males, 10 females)

(Values are means with their standard errors)

\begin{tabular}{lrc}
\hline & Mean & \multicolumn{1}{c}{ SE } \\
\hline Age (years) & 54.19 & 1.62 \\
Weight $(\mathrm{kg})$ & 73.69 & 2.72 \\
BMI $\left(\mathrm{kg} / \mathrm{m}^{2}\right)$ & 25.93 & 0.62 \\
Total cholesterol (mmol/l) & 6.09 & 0.18 \\
LDL-cholesterol (mmol/l) & 3.91 & 0.12 \\
HDL-cholesterol (mmol/l) & 1.28 & 0.07 \\
TAG (mmol/l) & 1.77 & 0.25 \\
\hline
\end{tabular}

\section{Plasma lipid concentrations}

Table 4 lists plasma lipid concentrations at the end of each treatment phase. Supplementation of an OO-based diet with either PS-SO or PS-OO resulted in reduced $(P=0.0218$ and $0 \cdot 0185$, respectively) LDL-C levels compared with control $\mathrm{OO}$, but there was only a mild tendency towards a reduction $(P=0.0839)$ in TC levels. TC:HDL-C ratios following PSSO treatment were lower $(P=0 \cdot 0018)$ compared with control $\mathrm{OO}$, but they were not significantly different from those observed with PS-OO. Consumption of the PS-matrices did not influence plasma HDL-C or TAG (fasting and postprandial) concentrations (Table 4).

The effects of the dietary fats and PS matrices on apo concentrations are also presented in Table 4. Apo A-I concentrations were higher $(P=0.0052$ and $P<0.0001)$ following PS-OO administration relative to control OO-diet and PS-SO, respectively, presumably due to differences in baseline values $(P<0 \cdot 0001)$. PS-containing diets had a strong tendency to induce $(P=0.0577)$ lower $(10-11 \%$, change from baseline) apo B-100 concentrations. This was associated with a mild tendency towards decreased $(P=0 \cdot 1030)$ LDL-C:apo B ratios, especially following the PS-OO treatment (an effect size of 0.47). Apo B-100:apo A-I ratios were lower $(P=0 \cdot 0052)$ with
PS-SO (6\%, relative to baseline) and, to a lesser degree $(P=0.2057)$, with PS-OO (4\%, relative to baseline) administrations compared with the control OO-diet. The effect of PS-SO consumption (an effect size of 0.35) on apo B-100:apo A-I ratios did not differ $(P=0.8698)$ from the effect of PS-OO supplementation (an effect size of 0.31).

Plasma Lp(a) concentrations were not altered $(P=0 \cdot 1182)$ by the dietary treatments at the end of the feeding phases. When endpoint values were compared to baseline concentrations, however, consumption of PS-OO did not influence Lp(a) levels, while the control OO-based diet and PS-SO treatments resulted in an increase $(P=0.0050$ and $P=0.0421$, respectively) of $\mathrm{Lp}$ (a) concentrations (Fig. 1).

\section{Plasma lipid peroxide concentrations}

The dietary treatments did not impact $(P=0.1295)$ endpoint plasma TBARS concentrations. However, when baselines and endpoints were compared (Fig. 2 ), the consumption of PS-OO was shown to have resulted in reduced $(-13 \%$; $P=0.0097)$ TBARS levels, whereas the OO-based diet $(-10 \% ; P=0.0993)$ and the PS-SO $(-3 \% ; P=0.1640)$ treatments failed to produce a comparable effect.

\section{Plasma neutral sterol concentrations}

Consumption of PS-SO and PS-OO resulted in a statistically significant increase in plasma campesterol, stigmasterol, and $\beta$-sitosterol concentrations compared with the control OObased diet (Table 5). Similar observations were obtained when plasma PS concentrations were normalized to cholesterol levels, although to a somewhat larger extent. The concentration of cholesterol precursor, lathosterol and its ratio to cholesterol were elevated $(P=0.0031$ and 0.0268 , $P=0.0564$ and 0.0047$)$ by PS-SO and PS-OO treatments, respectively, compared with the control OO-diet.

Table 4. Fasting plasma lipid and apo concentrations in overweight, hyperlipidaemic subjects $(n 21)$ consuming different oil supplements varying in fatty acid and plant sterol content in separate diets each lasting 4 weeks

(Values are means with their standard errors)

\begin{tabular}{|c|c|c|c|c|c|c|c|}
\hline \multirow[b]{2}{*}{ Plasma lipid } & \multicolumn{2}{|c|}{ OO } & \multicolumn{2}{|c|}{ PS-SO } & \multicolumn{2}{|c|}{ PS-OO } & \multirow[b]{2}{*}{$P$ value* } \\
\hline & Mean & SE & Mean & SE & Mean & SE & \\
\hline \multicolumn{8}{|l|}{ Cholesterol } \\
\hline Total $(\mathrm{mmol} / \mathrm{l})$ & 5.90 & 0.22 & $5 \cdot 61$ & 0.21 & 5.49 & 0.25 & 0.0839 \\
\hline $\operatorname{LDL}(\mathrm{mmol} / \mathrm{l})$ & $3.83^{a}$ & 0.17 & $3.59^{b}$ & $0 \cdot 16$ & $3.48^{\mathrm{b}}$ & 0.19 & 0.0483 \\
\hline $\mathrm{HDL}(\mathrm{mmol} / \mathrm{l})$ & 1.29 & 0.07 & 1.29 & 0.07 & 1.23 & 0.07 & 0.1904 \\
\hline Total:HDL & $4.75^{\mathrm{a}}$ & $0 \cdot 18$ & $4.53^{\mathrm{b}}$ & 0.20 & $4 \cdot 70^{\mathrm{ab}}$ & 0.22 & 0.0142 \\
\hline \multicolumn{8}{|l|}{ TAG } \\
\hline Fasting $(\mathrm{mmol} / \mathrm{l})$ & 1.86 & 0.27 & 1.62 & 0.19 & 1.75 & 0.25 & 0.1402 \\
\hline Postprandial (mmol/l) & 2.63 & 0.21 & 2.56 & 0.23 & $2 \cdot 70$ & 0.28 & 0.9942 \\
\hline \multicolumn{8}{|l|}{ Apo } \\
\hline ApoA-I (g/l) & $1 \cdot 30^{\mathrm{a}}$ & 0.06 & $1 \cdot 30^{\mathrm{a}}$ & 0.06 & $1 \cdot 31^{\mathrm{b}}$ & 0.05 & $0.0001 \dagger$ \\
\hline ApoB-100 (g/l) & $1 \cdot 12$ & 0.05 & 1.06 & 0.06 & 1.09 & 0.06 & 0.0577 \\
\hline ApoB-100:Apo A-I & $0.89^{a}$ & 0.04 & $0.84^{\mathrm{b}}$ & 0.05 & $0.84^{\mathrm{ab}}$ & 0.05 & 0.0168 \\
\hline LDL cholesterol:apoB-100 & 3.49 & $0 \cdot 17$ & 3.47 & 0.14 & 3.28 & 0.12 & 0.1030 \\
\hline
\end{tabular}

OO, control olive oil; PS-SO, plant sterols esterified with sunflower oil fatty acids; PS-OO, plant sterols esterified with olive oil fatty acids.

* $P$ values obtained by repeated-measures ANOVA, with tbaseline concentrations included in the model as covariates. Values of plasma lipid concentrations were normalized using a log transformation.

a,b Values not sharing a common superscript letter are significantly different at $P<0.05$. 


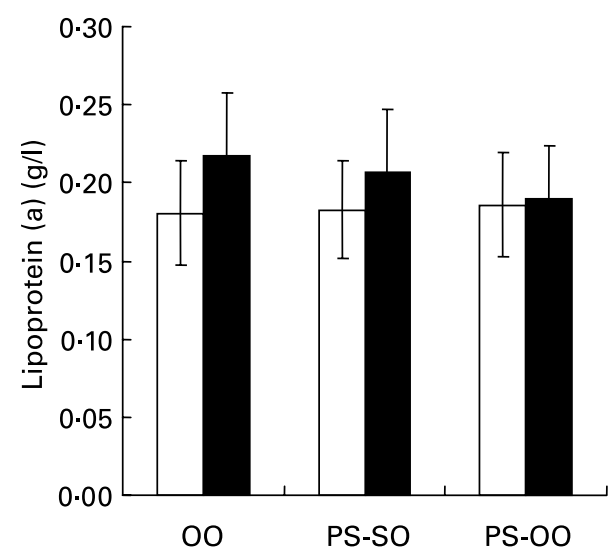

Fig. 1. Lipoprotein(a) (Lp(a)) levels in blood were measured at baseline ( $\square$ ) and after treatment $(\boldsymbol{\square})$. Values are means, with their standard errors shown by vertical bars, of $L p(a)$ concentrations of twenty-one patients. Statistical significance between the baseline and endpoint values was determined by the two-tailed paired-Student's $t$ test for the $O O(P=0.005)$ and the PS-SO $(P=0.0421)$ treatments but not for PS-OO $(P=0.8123)$. OO, control olive oil; PS-SO, plant sterols esterified with sunflower oil fatty acids; PS-OO, plant sterols esterified with olive oil fatty acids.

\section{Discussion}

Our results suggest that supplementation of an OO-based diet with $\mathrm{OO}$ fatty acids esterified to PS and mixed with dietary DAG reduces LDL-C levels and could lower LDL susceptibility to oxidation compared with an OO-based diet in hypercholesterolaemic mildly-overweight subjects. Consumption of both PS-OO and PS-SO diets favoured comparable beneficial reductions of CHD-related risk factors. However, in the context of an OO background diet, PS-OO feeding improved plasma antioxidant properties and protected against the increase in Lp(a) levels over the study period, while PSSO supplementation did not show such an action.

In the current study, PS-OO and PS-SO supplementation to the base OO-diet tended to reduce TC concentrations by -8 and $-6 \%$, relative to baseline respectively. Importantly, we have shown that ingestion of $1.7 \mathrm{~g} / \mathrm{d}$ PS esterified to OO or

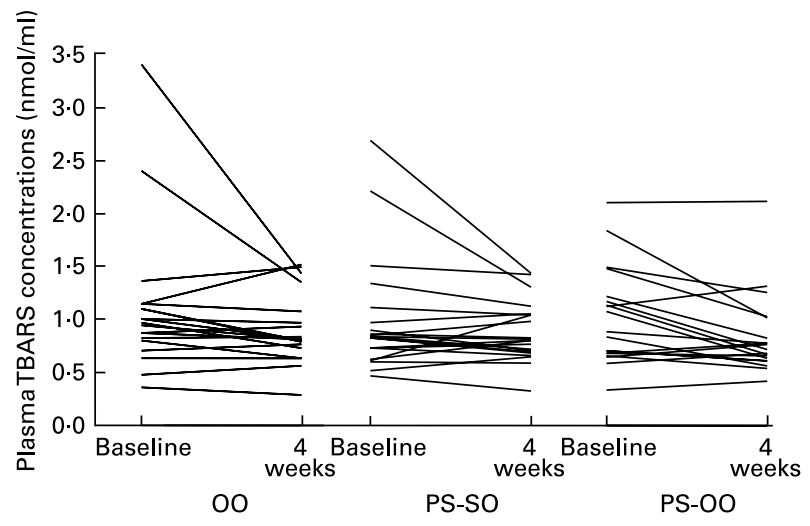

Fig. 2. Plasma thiobarbituric acid reactive substance (TBARS) levels in the LDL fraction were measured at baseline and endpoint (4 weeks) of each of three feeding phases ( $n 21$ subjects). Statistical significance between the baseline and endpoint values was determined using the two-tailed pairedStudent's $t$ test only for the PS-OO treatment. $(P=0.0097)$, but not for OO $(P=0.0993)$ and the PS-SO $(P=0.1640)$ treatments. OO: control olive oil; PS-SO: plant sterols esterified with sunflower oil fatty acids; PS-OO: plant sterols esterified with olive oil fatty acids.
SO fatty acids significantly decreased LDL-C concentrations by $6-9 \%$ compared to the base OO-diet. These decreases are consistent with results from a recent meta-analysis ${ }^{6}$, in which an intake of $1.5-1.9 \mathrm{~g}$ PS /d was associated with a $7 \cdot 0-10 \cdot 1 \%$ reduction in LDL-C levels. Moreover, plasma levels of apo B-100 tended to lower with consumption of PS diets, but to a somewhat lesser extent than LDL-C concentrations. These observations suggest that the PS treatments may have affected the cholesterol content of the LDL particles more than their number. On the other hand, there was a significant reducing effect of PS-containing treatments on apo B100:apo A-I ratio, suggesting that, in fact, these diets favour a beneficial suppression of apo B-100 levels compared with the control OO-diet. Taken together, our findings suggest that supplementation with PS provides superior protection against coronary artery disease risk factors than a healthy OO-based diet.

In this study, the PS concentrations in plasma increased following consumption of both PS-SO and PS-OO as compared with the base OO-diet. Plasma PS concentrations are naturally low since they are poorly absorbed. Nevertheless, high PS intake has been consistently shown to substantially increase circulating PS concentrations ${ }^{30,31}$. In the current study, however, the degree of elevation in plasma PS concentrations and their ratios to cholesterol due to PS consumptions were 23-fold lower than what we had previously observed, when PS were administered equally across two to three daily meals ${ }^{31}$. Taken together with the somewhat limited LDL-C lowering effect, these findings suggest that a single morning dose of PS may result in a lower PS bioavailability and therefore lesser efficacy. The link between PS bioavailability and treatment efficacy warrants further investigation.

Compared with the baseline values, the serum lipid peroxides associated with LDL particles were significantly reduced following PS-OO treatment. Early publications suggested that OO consumption resulted in LDL enrichment with oleic acid and, consequently, in a greater resistance to oxidation $^{32}$. Furthermore, a diet enriched in MUFA, rather than PUFA, was shown to inhibit LDL oxidation ${ }^{19,21,33}$. The presence of high levels of PS in $\operatorname{diet}^{34}$ or in vitro ${ }^{35}$ has been associated with decreased lipid peroxidation. Interestingly, similar observations were recently noted following administration of MUFA-enriched PS mixed with DAG to atherosclerotic apo $\mathrm{E}$ deficient mice ${ }^{36}$. Therefore, the antioxidant properties of MUFA-diets and PS could have contributed, at least in part, to the reduction in TBARS concentrations observed in our study on PS-OO.

In the current study, OO-diet and PS-SO supplementation resulted in increased $\mathrm{Lp}(\mathrm{a})$ levels over the study period, whereas no such deleterious effect was observed following PS-OO consumption. Elevated concentrations of $\mathrm{Lp}(\mathrm{a})$ have been suggested to be a risk factor for a variety of atherosclerotic and thrombotic disorders ${ }^{37,38}$. The atherogenicity of $\mathrm{Lp}$ (a) may be mediated, at least in part, by associated proinflammatory oxidized phospholipids ${ }^{38,39}$, but the link between Lp(a) and LDL oxidation in response to dietary modifications remains unclear. Although $\mathrm{OO}$ was shown in some studies to protect LDL from oxidation ${ }^{40,41}$, there are several reports in which its consumption resulted in elevated $\mathrm{Lp}$ (a) concentrations $^{42,43}$. Likewise, PUFA-enriched diets have been shown to increase $\mathrm{Lp}$ (a) levels ${ }^{44}$, presumably via interacting 
Table 5. Plasma plant sterol and cholesterol precursor concentrations following the consumption of each dietary treatment by mildly-overweight hypercholesterolaemic subjects $(n 21)$

(Values are means with their standard errors)

\begin{tabular}{|c|c|c|c|c|c|c|c|}
\hline \multirow[b]{2}{*}{ Plasma sterol } & \multicolumn{2}{|c|}{ ০০ } & \multicolumn{2}{|c|}{ PS-SO } & \multicolumn{2}{|c|}{ PS-OO } & \multirow[b]{2}{*}{$P$ value* } \\
\hline & Mean & SE & Mean & SE & Mean & SE & \\
\hline Lathosterol ( $\mu \mathrm{mol} / \mathrm{l})$ & $6.03^{a}$ & 0.75 & $6 \cdot 42^{b}$ & 0.53 & $7 \cdot 21^{\mathrm{ab}}$ & 0.90 & $0.0085 \dagger$ \\
\hline Campesterol $(\mu \mathrm{mol} / \mathrm{l})$ & $9 \cdot 26^{a}$ & 0.83 & $18 \cdot 11^{\mathrm{b}}$ & 1.75 & $18 \cdot 68^{b}$ & $2 \cdot 07$ & $<0.0001$ \\
\hline Stigmasterol $(\mu \mathrm{mol} / \mathrm{l})$ & $4.56^{\mathrm{a}}$ & 0.67 & $4 \cdot 65^{\mathrm{b}}$ & 0.73 & $5 \cdot 20^{\mathrm{b}}$ & 0.79 & $0.0282 \dagger$ \\
\hline$\beta$-sitosterol $(\mu \mathrm{mol} / \mathrm{l})$ & $5.48^{\mathrm{a}}$ & 0.61 & $7 \cdot 62^{\mathrm{b}}$ & 0.94 & $7 \cdot 73^{\mathrm{b}}$ & 0.96 & 0.0007 \\
\hline Lathosterol:cholesterol & $1.06^{\mathrm{a}}$ & 0.14 & $1 \cdot 22^{\mathrm{b}}$ & 0.14 & $1.43^{\mathrm{b}}$ & 0.19 & $0.0205 t$ \\
\hline Campesterol:cholesterol & $1.61^{\mathrm{a}}$ & 0.15 & $3 \cdot 36^{\mathrm{b}}$ & 0.36 & $3.71^{\mathrm{b}}$ & 0.47 & $<0.0001$ \\
\hline Stigmasterol:cholesterol & $0.84^{\mathrm{a}}$ & 0.14 & $0.93^{\mathrm{ab}}$ & 0.18 & $1 \cdot 16^{\mathrm{b}}$ & 0.25 & 0.0121 \\
\hline$\beta$-sitosterol:cholesterol & $0.93^{\mathrm{a}}$ & 0.08 & $1 \cdot 38^{\mathrm{b}}$ & 0.15 & $1.50^{\mathrm{b}}$ & 0.18 & $<0.0001$ \\
\hline
\end{tabular}

OO, control olive oil; PS-SO, plant sterols esterified with sunflower oil fatty acids; PS-OO, plant sterols esterified with olive oil fatty acids.

${ }^{*} P$ values obtained by repeated-measures ANOVA, with tbaseline concentrations included in the model as covariates.

Values of plasma lipids concentrations were normalized using a log transformation.

${ }^{a, b}$ Values not sharing a common superscript letter are significantly different at $P<0.05$.

with several transcription factors, such as NF- $\mathrm{B}$ and PPAR $\alpha^{45,46}$. In contrast, dietary DAG ingestion ${ }^{47}$ was recently associated with a slight but significant reduction in $\mathrm{Lp}(\mathrm{a})$ concentrations, possibly as a result of decreased hepatic fat contents. In our current study, the PS-OO treatment, which contained equivalent amounts of $\mathrm{OO}$ fatty acids as the control OO-diet, in addition with DAG maintained low Lp(a) levels. Although the levels of DAG administered in the PS-OO dietary matrix were considerably lower than the dose of DAG that had been shown to be effective in human clinical studies ${ }^{42,48}$, its presence could have contributed to maintaining $\mathrm{Lp}(\mathrm{a})$ levels. Taken together with the reduction in plasma TBARS concentrations, these results suggest that PS-OO may exert protective actions against oxidative stress.

In conclusion, our findings demonstrate that providing PScontaining matrices to hypercholesterolaemic, mildly overweight subjects fed with an OO-based diet results in optimized plasma lipid concentrations. Furthermore, consumption of PS-OO, but not PS-SO, may reduce the susceptibility of LDL to oxidative stress, which, in turn, could protect against increases in $\mathrm{Lp}(\mathrm{a})$ concentrations. Therefore, in the context of an OO-based diet, supplementation with PS-OO matrixed with DAG in OO may offer a greater level of protection against CHD than the traditional PS-SO formula to hypercholesterolaemic individuals.

\section{Acknowledgements}

We thank Dr Joel Lavoie who performed the lipid analyses at the Montreal Cardiology Institute and Dr William Parsons who was the study physician. We also acknowledge the staff of the Mary Emily Clinical Nutrition Research Unit. We thank Esther Shabtai from the Statistics Services Unit, Tel Aviv Sourasky Medical Centre, Israel for helping with the statistical analyses and Esther Eshkol for editorial assistance. We acknowledge Dr Tzafra Cohen and Dr Yael Herzog from Enzymotec Ltd. for their helpful comments on the manuscript. The sunflower oil esters of plant sterols were kindly provided by Unilever (USA). This study was funded by Enzymotec Ltd, Israel. Except for D. Pelled, who is the Director of
Clinical Studies at Enzymotec Ltd, none of the authors had any personal or financial conflict of interest.

\section{References}

1. Eisenberg D (1998) The importance of lowering cholesterol in patients with coronary heart disease. Clin Cardiol 21, 81-84.

2. Ross R (1999) Atherosclerosis-an inflammatory disease. $N$ Engl $J$ Med 340, 115-126.

3. Witztum JL \& Steinberg D (1991) Role of oxidized low density lipoprotein in atherogenesis. J Clin Invest 88, 1785-1792.

4. Meisinger C, Baumert J, Khuseyinova N, Loewel H \& Koenig W (2005) Plasma oxidized low-density lipoprotein, a strong predictor for acute coronary heart disease events in apparently healthy, middle-aged men from the general population. Circulation 112, 651-657.

5. Pollak OJ (1953) Reduction of blood cholesterol in man. Circulation 7, 702-706.

6. Katan MB, Grundy SM, Jones P, Law M, Miettinen $\mathrm{T}$ \& Paoletti R (2003) Efficacy and safety of plant stanols and sterols in the management of blood cholesterol levels. Mayo Clin Proc 78, 965-978.

7. Ikeda I \& Sugano M (1983) Some aspects of mechanism of inhibition of cholesterol absorption by beta-sitosterol. Biochim Biophys Acta 732, 651-658.

8. Heinemann T, Kullak-Ublick GA, Pietruck B \& von Bergmann K (1991) Mechanisms of action of plant sterols on inhibition of cholesterol absorption. Comparison of sitosterol and sitostanol. Eur J Clin Pharmacol 40, Suppl. 1, S59-S63.

9. Ostlund RE Jr (2004) Phytosterols and cholesterol metabolism. Curr Opin Lipidol 15, 37-41.

10. Gremaud G, Dalan E, Piguet C, Baumgartner M, Ballabeni P, Decarli B, Leser ME, Berger A \& Fay LB (2002) Effects of non-esterified stanols in a liquid emulsion on cholesterol absorption and synthesis in hypercholesterolemic men. Eur J Nutr 41, 54-60.

11. Meguro S, Higashi K, Hase T, Honda Y, Otsuka A, Tokimitsu I \& Itakura H (2001) Solubilization of phytosterols in diacylglycerol versus triacylglycerol improves the serum cholesterol-lowering effect. Eur J Clin Nutr 55, 513-517.

12. Ostlund RE Jr, Spilburg CA \& Stenson WF (1999) Sitostanol administered in lecithin micelles potently reduces cholesterol absorption in humans. Am J Clin Nutr 70, 826-831. 
13. Spilburg CA, Goldberg AC, McGill JB, Stenson WF, Racette SB, Bateman J, McPherson TB \& Ostlund RE Jr (2003) Fatfree foods supplemented with soy stanol-lecithin powder reduce cholesterol absorption and LDL cholesterol. J Am Diet Assoc 103, 577-581.

14. Weststrate JA \& Meijer GW (1998) Plant sterol-enriched margarines and reduction of plasma total- and LDL-cholesterol concentrations in normocholesterolaemic and mildly hypercholesterolaemic subjects. Eur J Clin Nutr 52, 334-343.

15. Demonty I, Chan YM, Pelled D \& Jones PJ (2006) Fish-oil esters of plant sterols improve the lipid profile of dyslipidemic subjects more than do fish-oil or sunflower oil esters of plant sterols. Am J Clin Nutr 84, 1534-1542.

16. Aravanis C, Corcondilas A, Dontas AS, Lekos D \& Keys A (1970) Coronary heart disease in seven countries. IX. The Greek islands of Crete and Corfu. Circulation 41, I88-100.

17. Stark AH \& Madar Z (2002) Olive oil as a functional food: epidemiology and nutritional approaches. Nutr Rev 60, 170-176.

18. Mattson FH \& Grundy SM (1985) Comparison of effects of dietary saturated, monounsaturated, and polyunsaturated fatty acids on plasma lipids and lipoproteins in man. $J$ Lipid Res 26, 194-202.

19. Kratz M, Cullen P, Kannenberg F, Kassner A, Fobker M, Abuja PM, Assmann G \& Wahrburg U (2002) Effects of dietary fatty acids on the composition and oxidizability of low-density lipoprotein. Eur J Clin Nutr 56, 72-81.

20. Kris-Etherton PM, Pearson TA, Wan Y, Hargrove RL, Moriarty K, Fishell V \& Etherton TD (1999) High-monounsaturated fatty acid diets lower both plasma cholesterol and triacylglycerol concentrations. Am J Clin Nutr 70, 1009-1015.

21. Puiggros C, Chacon P, Armadans LI, Clapes J \& Planas M (2002) Effects of oleic-rich and omega-3-rich diets on serum lipid pattern and lipid oxidation in mildly hypercholesterolemic patients. Clin Nutr 21, 79-87.

22. Reaven PD \& Witztum JL (1996) Oxidized low density lipoproteins in atherogenesis: role of dietary modification. Annu Rev Nutr 16, 51-71.

23. Berger A, Jones PJ \& Abumweis SS (2004) Plant sterols: factors affecting their efficacy and safety as functional food ingredients. Lipids Health Dis 3, 5.

24. Mifflin MD, St Jeor ST, Hill LA, Scott BJ, Daugherty SA \& Koh YO (1990) A new predictive equation for resting energy expenditure in healthy individuals. Am $J$ Clin Nutr 51, 241-247.

25. Friedewald WT, Levy RI \& Fredrickson DS (1972) Estimation of the concentration of low-density lipoprotein cholesterol in plasma, without use of the preparative ultracentrifuge. Clin Chem 18, 499-502.

26. Ntanios FY \& Jones PJ (1998) Effects of variable dietary sitostanol concentrations on plasma lipid profile and phytosterol metabolism in hamsters. Biochim Biophys Acta 1390, 237-244.

27. Gidez LI, Miller GJ, Burstein M, Slagle S \& Eder HA (1982) Separation and quantitation of subclasses of human plasma high density lipoproteins by a simple precipitation procedure. J Lipid Res 23, 1206-1223.

28. Lefevre G, Beljean-Leymarie M, Beyerle F, Bonnefont-Rousselot D, Cristol JP, Therond P \& Torreilles J (1998) Evaluation of lipid peroxidation by measuring thiobarbituric acid reactive substances. Ann Biol Clin (Paris) 56, 305-319.

29. Jones PJ, Ntanios FY, Raeini-Sarjaz M \& Vanstone CA (1999) Cholesterol-lowering efficacy of a sitostanol-containing phytosterol mixture with a prudent diet in hyperlipidemic men. Am J Clin Nutr 69, 1144-1150.

30. Jones PJ, Vanstone CA, Raeini-Sarjaz M \& St-Onge MP (2003) Phytosterols in low- and nonfat beverages as part of a controlled diet fail to lower plasma lipid levels. J Lipid Res 44, 1713-1719.

31. Vanstone CA, Raeini-Sarjaz M, Parsons WE \& Jones PJ (2002) Unesterified plant sterols and stanols lower LDL-cholesterol concentrations equivalently in hypercholesterolemic persons. Am J Clin Nutr 76, 1272-1278.

32. Aviram M \& Eias K (1993) Dietary olive oil reduces low-density lipoprotein uptake by macrophages and decreases the susceptibility of the lipoprotein to undergo lipid peroxidation. Ann Nutr Metab 37, 75-84.

33. Berry EM, Eisenberg S, Haratz D, Friedlander Y, Norman Y, Kaufmann NA \& Stein Y (1991) Effects of diets rich in monounsaturated fatty acids on plasma lipoproteins-the Jerusalem Nutrition Study: high MUFAs vs high PUFAs. Am J Clin Nutr 53, 899-907.

34. Homma Y, Ikeda I, Ishikawa T, Tateno M, Sugano M \& Nakamura H (2003) Decrease in plasma low-density lipoprotein cholesterol, apolipoprotein B, cholesteryl ester transfer protein, and oxidized low-density lipoprotein by plant stanol ester-containing spread: a randomized, placebo-controlled trial. Nutrition 19, 369-374.

35. van Rensburg SJ, Daniels WM, van Zyl JM \& Taljaard JJ (2000) A comparative study of the effects of cholesterol, betasitosterol, beta-sitosterol glucoside, dehydroepiandrosterone sulphate and melatonin on in vitro lipid peroxidation. Metab Brain Dis 15, 257-265.

36. Fuhrman B, Plat D, Herzog Y \& Aviram M (2007) Consumption of a novel dietary formula containing plant sterols esterified to canola oil fatty acids and 1,3-diacylglycerol in a canola oil matrix reduces oxidative stress in the atherosclerotic apolipoprotein E-deficient mice. J Agric Food Chem 55, 2028-2033.

37. Boffa MB, Marcovina SM \& Koschinsky ML (2004) Lipoprotein(a) as a risk factor for atherosclerosis and thrombosis: mechanistic insights from animal models. Clin Biochem 37, $333-343$.

38. Tsimikas S, Lau HK, Han KR, Shortal B, Miller ER, Segev A, Curtiss LK, Witztum JL \& Strauss BH (2004) Percutaneous coronary intervention results in acute increases in oxidized phospholipids and lipoprotein(a): short-term and long-term immunologic responses to oxidized low-density lipoprotein. Circulation 109, 3164-3170.

39. Tsimikas S, Bergmark C, Beyer RW, Patel R, Pattison J, Miller E, Juliano J \& Witztum JL (2003) Temporal increases in plasma markers of oxidized low-density lipoprotein strongly reflect the presence of acute coronary syndromes. J Am Coll Cardiol 41, 360-370.

40. Aviram M (1996) Interaction of oxidized low density lipoprotein with macrophages in atherosclerosis, and the antiatherogenicity of antioxidants. Eur J Clin Chem Clin Biochem 34, 599-608.

41. Fito M, Covas MI, Lamuela-Raventos RM, Vila J, Torrents L, de la Torre C \& Marrugat J (2000) Protective effect of olive oil and its phenolic compounds against low density lipoprotein oxidation. Lipids 35, 633-638.

42. Mensink RP \& Katan MB (1992) Effect of dietary fatty acids on serum lipids and lipoproteins. A meta-analysis of 27 trials. Arterioscler Thromb 12, 911-919.

43. Vessby B, Unsitupa M, Hermansen K, et al. (2001) Substituting dietary saturated for monounsaturated fat impairs insulin sensitivity in healthy men and women: The KANWU Study. Diabetologia 44, 312-319.

44. Silaste ML, Rantala M, Alfthan G, Aro A, Witztum JL, Kesaniemi YA \& Horkko S (2004) Changes in dietary fat intake alter plasma levels of oxidized low-density lipoprotein and lipoprotein(a). Arterioscler Thromb Vasc Biol 24, 498-503.

45. Maziere C, Conte MA, Degonville J, Ali D \& Maziere JC (1999) Cellular enrichment with polyunsaturated fatty acids induces an 
oxidative stress and activates the transcription factors AP1 and NFkappaB. Biochem Biophys Res Commun 265, 116-122.

46. Tai ES, Corella D, Demissie S, Cupples LA, Coltell O, Schaefer EJ, Tucker KL \& Ordovas JM (2005) Polyunsaturated fatty acids interact with the PPARA-L162V polymorphism to affect plasma triglyceride and apolipoprotein C-III concentrations in the Framingham Heart Study. J Nutr 135, 397-403.
47. Teramoto $\mathrm{T}$, Watanabe $\mathrm{H}$, Ito $\mathrm{K}$, Omata $\mathrm{Y}$, Furukawa $\mathrm{T}$, Shimoda K, Hoshino M, Nagao T \& Naito S (2004) Significant effects of diacylglycerol on body fat and lipid metabolism in patients on hemodialysis. Clin Nutr 23, 1122-1126.

48. Rudkowska I, Roynette CE, Demonty I, Vanstone CA, Jew S \& Jones PJ (2005) Diacylglycerol: efficacy and mechanism of action of an anti-obesity agent. Obes Res 13, 1864-1876. 